\title{
Evolution of Highly Polymorphic T Cell Populations in Siblings with the Wiskott-Aldrich Syndrome
}

\author{
Maxim I. Lutskiy ${ }^{1,2}$, Jun Y. Park ${ }^{1}$, Susanna K. Remold ${ }^{39}$, Eileen Remold-O'Donnell ${ }^{1,29 *}$
}

1 Immune Disease Institute, Harvard Medical School, Boston, Massachusetts, United States of America, 2 Department of Pediatrics, Harvard Medical School, Boston, Massachusetts, United States of America, 3 Program on Disease Evolution, Department of Biology, University of Louisville, Louisville, Kentucky, United States of America

\begin{abstract}
Population level evolutionary processes can occur within a single organism when the germ line contains a mutation that confers a cost at the level of the cell. Here we describe how multiple compensatory mutations arose through a withinindividual evolutionary process in two brothers with the immune deficiency Wiskott-Aldrich Syndrome (WAS). As a result, both brothers have T lymphocyte populations that are highly polymorphic at the locus of the germ line defect, and no single allele achieves fixation. WASP, the gene product affected in this disease, is specific to white blood cells where it is responsible for regulating actin cytoskeleton dynamics in a wide range of cellular responses. The brothers inherited a rare allele predicted to result in truncated WASP lacking the carboxy-terminal VCA domains, the region that directly catalyzes actin filament generation. Although the brothers' T cell populations are highly polymorphic, all share a corrective effect relative to the inherited allele in that they restore the VCA domain. This indicates massive selection against the truncated germ line allele. No single somatic allele becomes fixed in the circulating $T$ cell population of either brother, indicating that a regulated step in maturation of the affected cell lineage is severely compromised by the germ line allele. Based on the finding of multiple somatic mutations, the known maturation pathway for T-lineage cells and the known defects of T cells and precursor thymocytes in mice with truncated WASP, we hypothesize that the presence of truncated WASP (WASP $\triangle$ VCA) confers an extreme disadvantage in early developing thymocytes, above and beyond the known cost of absence of fulllength WASP, and that the disadvantage likely occurs through dominant negative competition of WASP $\triangle$ VCA with N-WASP, a protein that otherwise partially compensates for WASP absence in developing thymocytes.
\end{abstract}

Citation: Lutskiy MI, Park JY, Remold SK, Remold-O'Donnell E (2008) Evolution of Highly Polymorphic T Cell Populations in Siblings with the Wiskott-Aldrich Syndrome. PLoS ONE 3(10): e3444. doi:10.1371/journal.pone.0003444

Editor: Adam J. Ratner, Columbia University, United States of America

Received June 16, 2008; Accepted September 10, 2008; Published October 20, 2008

Copyright: (c) 2008 Lutskiy et al. This is an open-access article distributed under the terms of the Creative Commons Attribution License, which permits unrestricted use, distribution, and reproduction in any medium, provided the original author and source are credited.

Funding: This work was supported by National Institutes of Health grants HL59561, Al39574 and HL081407, National Science Foundation grant DEB-0452163, and the Jeffrey Modell Foundation.

Competing Interests: The authors have declared that no competing interests exist.

*E-mail: remold@cbrinstitute.org

9 These authors contributed equally to this work.

\section{Introduction}

The cells comprising a multicellular organism reproduce and compete in particular local environments, much as do free-living organisms. When genetic differences arise within a cell type, evolution can ensue within the host organism. The classic example of this phenomenon is cancer - a somatic mutant arises and increases in frequency relative to cells of the germ line genotype due to a selective advantage in the local environment. In cancer, selection at the level of the cell type differs from selection at the level of the host organism because the role of the affected cell type in the multicellular organism is at odds with maximizing the number of its progeny cells.

We present an instance involving a germ line allele causing disease at the level of the whole organism. In contrast to cancer causing mutations, in this situation the somatic mutations that increase in frequency due to selection at the level of the cell also confer benefit to the whole organism. This coincident benefit means that identifying the strength, timing and local environment in which the somatic mutation(s) confer advantage will contribute to a better understanding of how the affected cell type normally functions within the multicellular organism.
For genetic hematopoietic diseases, somatic mutations that are corrective at the level of the whole organism may have a special propensity to reach high frequency in the cell population. This is because a successful somatic mutant with higher fitness relative to hematopoietic cells carrying the inherited allele has long survival and a long-term influence on the organism's fate. In addition, hematopoietic cells function throughout the body, allowing compensatory somatic mutants to affect the organism systemically. However somatic mutations can only benefit the whole organism to the extent that (i) at the level of the cell type, selection on a newly arising somatic mutant is strongly positive and (ii) that selection against the germ line allele occurs early enough in the cell lineage that sufficient divisions remain for a mutation-corrected allele to increase in frequency in the cell population.

Here we describe a situation where the balance of these two factors is such that not one, but many, somatic mutations are detected. This occurred independently and in parallel in the T cell populations of two brothers who share the same germ line mutation of the gene Wiskott Aldrich Syndrome protein (WASP). We document these numerous compensatory somatic alleles and explore the timing, location and the nature of their selective 
advantage, thereby deducing that the gene product, also called WASP, affects $\mathrm{T}$ cell populations in at least two distinct contexts.

\section{Wiskott-Aldrich Syndrome (WAS) and WASP Function}

Wiskott-Aldrich syndrome (WAS) (MIM \#30100) is an Xlinked combined primary immunodeficiency disease [1] causing bleeding due to thrombocytopenia and numerous immune defects (reviewed in [2]). Histocompatibility-matched hematopoietic stem cell transplantation is currently the only cure [3] for WAS. For patients for whom no histocompatible matched donor is available, life expectancy is still short, particularly for patients with WASPnegative mutations [4]. In part for this reason, WAS is among those conditions for which hematopoietic stem cell gene therapy is under intense study $[5,6]$.

Immune dysfunction in this disease varies from mild to lifethreatening, depending to a large extent on whether the inherited mutation supports expression of some level of WASP in the patient's blood cells (milder disease) or leads to WASP absence (severe disease) [4]. In unusual cases, the impact of severe germ line WASP mutations is mitigated by somatic reversion or somatic second site mutation [7-13].

WASP couples extracellular stimulation of the cell to rapid intracellular remodeling of the actin-based cytoskeleton (reviewed in [14]). WASP is expressed only in white blood cells; its closely related homolog N-WASP is broadly expressed. Both proteins assume an autoinhibited (closed) conformation in resting cells [15]. WASP's function in cytoskeletal rearrangement is best understood in $\mathrm{T}$ lymphocytes. In these cells activation occurs when antigens bind to the $\mathrm{T}$ cell antigen receptor ( $\mathrm{T}$ cell receptor; TCR). WASP is then recruited to the newly generated immunological synapse between the antigen presenting cell and the $\mathrm{T}$ cell [16]. At the immune synapse, activating mediators such as the lipid phosphoinositol 4,5-biphosphate (PIP2) and cdc42, a GTPase, bind to WASP, releasing autoinhibition and unmasking WASP's Cterminal VCA (verprolin homology, cofilin homology, acidic) domains. The VCA domains cooperate with a complex of actin related proteins (Arp2/3 complex) to generate new actin filaments $[15,17]$ that are required for altering cell polarity, proliferative response and further cell differentiation. Through this process, WASP is critical for optimal proliferative response of $\mathrm{T}$ lymphocytes and in a similar manner for B lymphocytes. WASP is also expressed in other white blood cells: monocytes, neutrophils, NK lymphocytes and platelets, where its actin remodeling activity contributes to migration, phagocytosis and other functions (reviewed in [14]).

WASP is also believed to contribute to maturation of progenitor $\mathrm{T}$ and $\mathrm{B}$ lymphoid cells. This inference rests on a cross-sectional study showing that WAS patients have decreased numbers of mature $\mathrm{T}$ and $\mathrm{B}$ lymphocytes in their blood relative to agematched healthy normal individuals [18]. The deficit of total blood $\mathrm{T}$ and $\mathrm{B}$ cells primarily reflects the decrease of the initially produced antigen-inexperienced "naïve" $\mathrm{T}$ and $\mathrm{B}$ cells rather than antigen-experienced "memory" cells.

The brothers studied here inherited a rare WASP mutation (G1305 delete) predicted to result in a truncated protein that lacks the VCA domains (WASPAVGA). Their mother is a confirmed carrier. As is typical for WAS carriers, her mature blood cells are normal in number and phenotype, reflecting selective survival and/or proliferation of progenitor cells with the active $\mathrm{X}$ chromosome bearing normal WASP [19]. In the three other patients reported to carry this mutation (two of whom were maternal uncles of these brothers), the mutation caused severe WAS [20]. In contrast, the brothers reached adulthood with only moderate disease. Here we describe their somatic alleles and investigate their selective advantage in T-lymphopoiesis. Because during T-lymphopoiesis selection for survival and replication at the level of the thymocyte is concordant with these cells' normal contribution to the whole organism's phenotype, this selection sheds light on the normal role of WASP in T-lymphopoiesis.

\section{Results}

\section{Identifying Cell Types Experiencing Selection for WASP Function}

To resolve the discordancy of the brothers' severe germ line mutation and their moderate disease course, we subjected their blood cells to quantitative and qualitative analyses. This was done by staining blood samples with antibodies to cell surface "marker" proteins and analyzing the stained cells by flow cytometry. Table 1 shows the quantitation of their lymphocytes compared to agematched normal healthy individuals. The results reflect the previously described pattern for this disease albeit at the more extreme end: the brothers share significant deficits of $\mathrm{T}$ cells (both CD4 and CD8) and B cells but have normal numbers of natural killer cells (NK cells) [18]. In particular, their memory CD4 and CD8 $\mathrm{T}$ cells were in the normal range, but the number of their naïve, i.e., antigen-inexperienced, CD4 and CD8 cells were decreased by more than $75 \%$ relative to normal values. Notably, the patterns in the two brothers are almost identical.

Because cells of previously studied WAS patients with truncation mutations have revealed little or no WASP [4,21], we used flow cytometry to determine whether any WASP is expressed in the brothers' cells. Peripheral blood mononuclear cells (PBMC) were permeabilized, stained intracellularly with fluorescent antibodies to WASP, and analyzed to detect presence vs. absence of the WASP protein at the level of single cells. Whereas monocytes of the brothers were WASP-negative, appearing unstained or dimly stained, their lymphocytes included a minor population of brightly staining WASP-positive cells (Figure 1A, left and middle). WASP-positive cells were more prevalent among $\mathrm{T}$ lymphocytes $\left(\mathrm{CD}^{+}\right.$cells), comprising $56 \%$ for the younger brother (patient 2) (Figure 1A, right) and 58\% for his sibling (patient 1, not shown). Of note, the intensity of fluorescent label, an approximate measure of WASP density, was comparable for the WASP-positive subset of patient $\mathrm{T}$ cells and normal $\mathrm{T}$ cells

Table 1. Lymphocyte Populations in Patient Blood.

\begin{tabular}{|c|c|c|c|}
\hline \multirow[t]{2}{*}{ Cells } & \multicolumn{3}{|c|}{ Absolute cell count $\left(\times 10^{6} / \mathrm{ml}\right)$} \\
\hline & Patient 1 & Patient 2 & Normal $^{\text {ab }}$ \\
\hline Total lymphocytes & 0.96 & 1.08 & $1.68(1.48-2.00)^{*}$ \\
\hline T cells $\left(\mathrm{CD}^{+}{ }^{+} \mathrm{CD}_{4} 5^{+}\right)$ & 0.61 & 0.67 & $1.26(1.04-1.52)^{*}$ \\
\hline B cells $\left(\mathrm{CD} 19^{+} \mathrm{CD} 45^{+}\right)$ & 0.04 & 0.06 & $0.24(0.18-0.26)^{* *}$ \\
\hline NK cells $\left(\mathrm{CD} 16^{+} \mathrm{CD}^{2} 6^{+} \mathrm{CD}^{-}\right)$ & 0.30 & 0.20 & $0.18(0.13-0.37)^{\mathrm{ns}}$ \\
\hline Naïve CD4 cells $\left(C D 45 R^{+}\right)$ & 0.09 & 0.10 & $0.40(0.14-0.74)^{*}$ \\
\hline Memory CD4 cells (CD45RA ${ }^{-}$) & 0.32 & 0.49 & $0.42(0.32-0.48)^{\mathrm{ns}}$ \\
\hline Naïve CD8 cells $\left(\mathrm{CD}^{2} 5 \mathrm{RA}^{+} \mathrm{CCR7}{ }^{+}\right)$ & 0.005 & 0.006 & $0.22(0.18-0.34)^{*}$ \\
\hline Memory CD8 cells ${ }^{c}$ & 0.165 & 0.204 & $0.11(0.09-0.21)^{\mathrm{ns}}$ \\
\hline
\end{tabular}

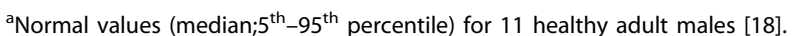
${ }^{b}$ Significance from one-tailed t-tests comparing cell counts of the normal healthy males to the brothers' counts: ${ }^{n s} p>0.05 ;{ }^{*} 0.01<p<0.05$; ${ }^{*}$ $0.001<\mathrm{p}<0.01$.

${ }^{c}$ Memory CD8 cells are the sum of $\mathrm{CD}^{+} \mathrm{CD} 45 \mathrm{RA}^{+} \mathrm{CCR}^{-}$and $\mathrm{CD} 8^{+} \mathrm{CD} 45 \mathrm{RA}$ cells.

doi:10.1371/journal.pone.0003444.t001 


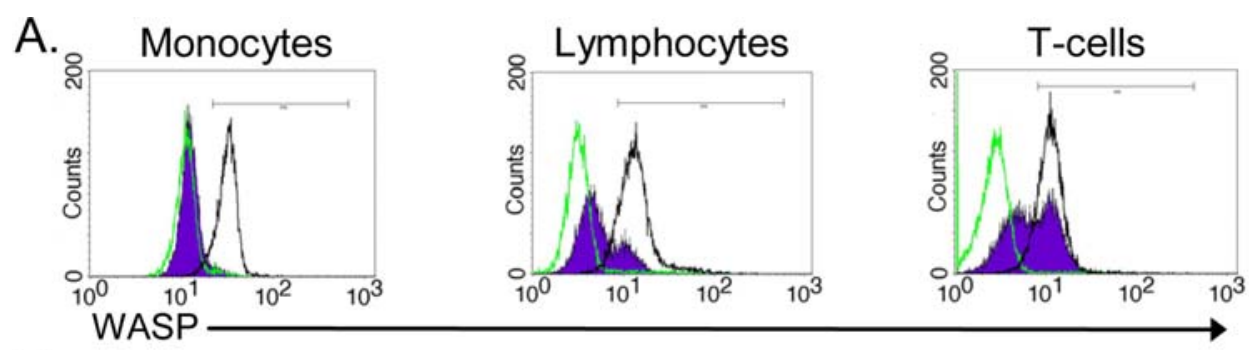

B.
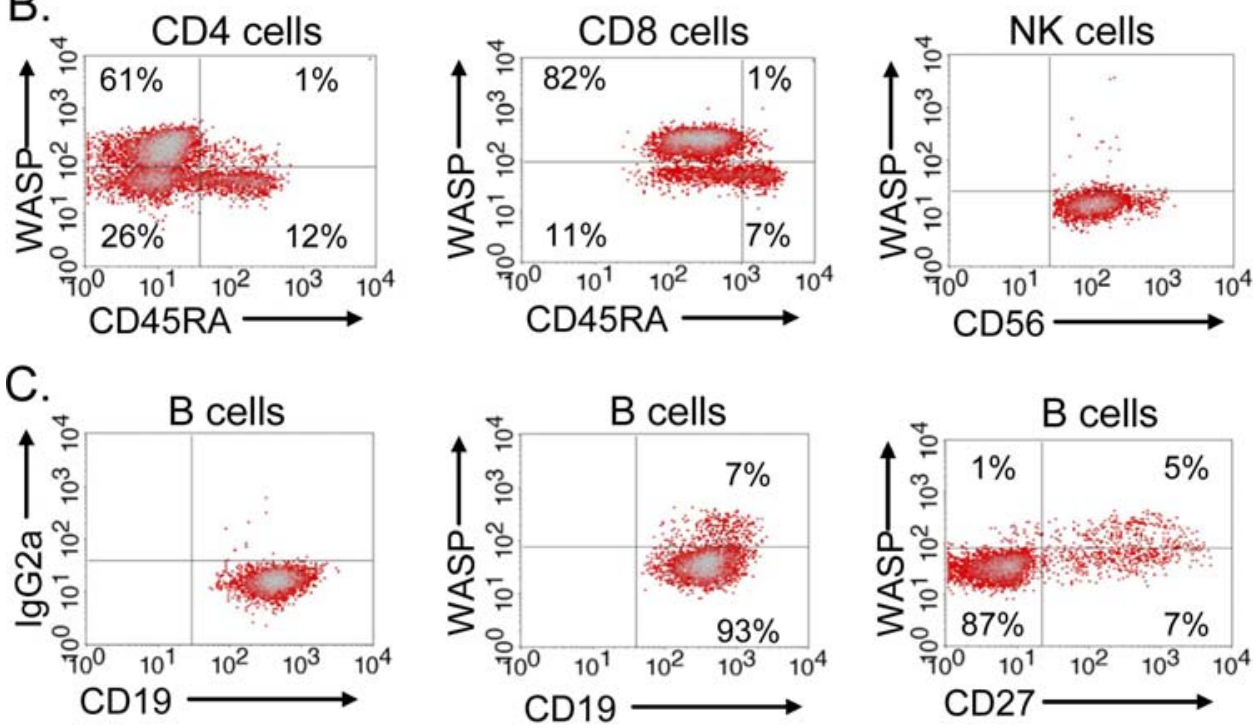

\section{Mean percent WASP-positive cells}

\begin{tabular}{|c|c|c|c|}
\hline Cells & total & $\begin{array}{c}\text { naïve } \\
\text { cells }\end{array}$ & $\begin{array}{c}\text { memory } \\
\text { cells }\end{array}$ \\
\hline CD4 cells & 59 & $<7$ & 68 \\
\hline CD8 cells & 85 & N.D. & 88 \\
\hline B cells & 6 & $1^{\mathrm{a}}$ & $42^{\mathrm{a}}$ \\
\hline NK cells & $\sim 0$ & - & - \\
\hline Monocytes & $\sim 0$ & - & - \\
\hline
\end{tabular}

a patient 2 only, (patient 1, ND)

Figure 1. WASP in Patient Blood Cells Revealed by Flow Cytometry. PBMC of the younger brother (patient 2) were stained intracellularly with B9 monoclonal antibody to WASP and, where indicated, were stained with surface marker antibodies. (A) Monocytes and lymphocytes. Shown are patient monocytes (left), total lymphocytes (middle), and T lymphocytes (CD3 ${ }^{+}$cells) (right) indicated by filled histograms; cells of a normal individual are indicated by black outlines and isotype control by green outlines. (B) T and NK lymphocytes. CD4 (CD4 ${ }^{+}$) and CD8 (CD8 ${ }^{\text {bright }}$ ) cells, and NK cells $\left(C D 56^{+} \mathrm{CD}^{-}\right)$stained for WASP and, where indicated, for CD45RA to distinguish T cell subsets. Numbers within quadrants indicate the percentage of cells. (C) B-lymphocytes. B cells $\left(\mathrm{CD} 19^{+}\right)$were stained with isotype control antibody (left) or WASP antibody (middle, right) and for CD27 to distinguish B-cell subsets (right). (D) Shown are the percent WASP-positive cells in different populations averaged across the two brothers. ND, not determined.

doi:10.1371/journal.pone.0003444.g001

(Figure 1A, right), suggesting that patient cells that express WASP do so at normal or near normal levels. These T lymphocytes must either express more truncated WASP than other cells bearing the same genotype or they are WASP-positive because they bear a somatic allele.

WASP-positive cells were found in both CD4 and CD8 T-cells (Figure 1B, left and middle). Antibody to CD45RA, a stagespecific $T$ cell antigen, was used to distinguish naïve and memory cells [22]. WASP-positive cells were frequent among memory CD4 cells (CD45RA ${ }^{-}$, upper left quadrant) $(65 \%$ for patient $1 ; 70 \%$ for patient 2), but were infrequent $(\leq 7 \%)$ among naive CD4 cells
(CD45RA ${ }^{+}$, upper right quadrant). WASP-positive cells were also frequent among CD8 memory $\left(\mathrm{CD} 45 \mathrm{RA}^{-}\right)$cells of both patients $(89 \%, 88 \%)$ and infrequent in the small $\mathrm{CD}^{+} \mathrm{CD} 45 \mathrm{RA}^{+}$ population that includes the CD8 naïve cells. NK lymphocytes (NK cells) were uniformly WASP-negative (Figure 1B, right). These quantitative findings for the two brothers are compiled in Figure 1D.

A fraction of B lymphocytes $\left(\mathrm{CD} 19^{+}\right.$lymphocytes) were also WASP-positive, amounting to $7 \%$ for patient 2 (Figure $1 \mathrm{C}$, left and middle) and $4 \%$ for patient 1 (not shown). For patient 2 , the $\mathrm{B}$ cells were further subdivided. WASP-positive cells were negligible 
among his naïve (CD27-negative) cells $(\sim 1 \%)$ (Figure 1C, right), but frequent in the CD27-positive cells $(42 \%)$, which are B cells that have undergone differentiation and expansion in the periphery $[23,24]$.

\section{WASP Phenotype in Cell Types under Selection}

The patients' germ line mutation is a single nucleotide deletion in exon 10 (1305delG) [25]. The expected effect is frameshift and premature stop within exon 10 to generate truncated protein lacking the VCA domains required for actin remodeling (Figure 2A). To study the amount and size of the WASP protein in patient cell types for which flow cytometry data indicated selection on WASP function, we studied isolated PBMC (lymphocytes plus monocytes), neutrophils and lymphocytes by Western blot. Unlike flow cytometry, which compiles data for individual single cells, Western blot reports on protein isolated from cell populations. The blots were stained with antibodies directed against different epitopes of WASP. These are antibodies B9 and D1, directed against epitopes within the N-terminal 250 amino acids, and W485, an antibody directed against residues 485-502. All three antibodies detected full length WASP bands (apparent $63 \mathrm{kDa}$ ) in all analyzed blood cells of normal individuals as anticipated and detected similar size WASP bands at lower levels in patient PBMC and in lymphocytes but not in patient neutrophils [26] verified in Figure 2B). In addition, D1 and $\mathrm{B} 9$ antibodies detected a weaker band in patient PBMC, lymphocytes and neutrophils at the approximate position expected for truncated WASP (apparent $47 \mathrm{kDa}$ ). This $47 \mathrm{kDa}$ band was not found in cells of normal PBMC, lymphocytes or neutrophils. Blots of patient cells stained with the W485 antibody that reacts with an epitope at the extreme C-terminus failed to detect the $47 \mathrm{kDa}$ protein, further indicating that it is truncated WASP. Importantly, because the patients' full size protein $(\sim 63 \mathrm{kDa})$ was detected by the W485 antibody, the sequence at the C-terminus must be encoded by an allele with an in-frame C-terminal region in contrast with the inherited allele.

\section{Genetic Basis of Restored Phenotype in Patient T Cells}

When mRNA of patient 2 PBMC was reverse transcribed and amplified, the product was a single band of apparent normal size and amount (not shown). Both the bulk product and randomly selected clones had the germ line frameshift-stop sequence. However, one clone that was non-randomly selected for study because of its slightly smaller insert coded for WASP with an 18 bp deletion relative to the normal sequence (17 bp deletion flanking the germ line nucleotide deletion) (detailed below). This sequence would be consistent with a somatic second site mutation. On sequencing another "small insert", we were surprised to find a different mutation, a $20 \mathrm{bp}$ deletion flanking the germ line mutation. Although a few instances of multiple somatic mutations have been described for other primary immune deficiencies no WAS patient described at that time had more than one somatic allele (Discussion).

To sequence the somatic mutations, we amplified and cloned DNA of patient 2 PBMC and T cell DNA of both brothers. A total of 14 somatic WASP alleles were sequenced and are shown in Table 2. It is important to note that our cloning effort was not exhaustive and did not come close to a generating a saturated sample of the population of alleles coexisting in each brother (presented later), and so Table 2 should be viewed as a subset of the brothers' alleles, which may be biased toward alleles differing from the germ line allele in length.

The detected somatic alleles are of two types. The most frequent, found in all 8 clones for patient 2 and in 4 of 11 clones for patient 1 , are deletions that surround the germ line single
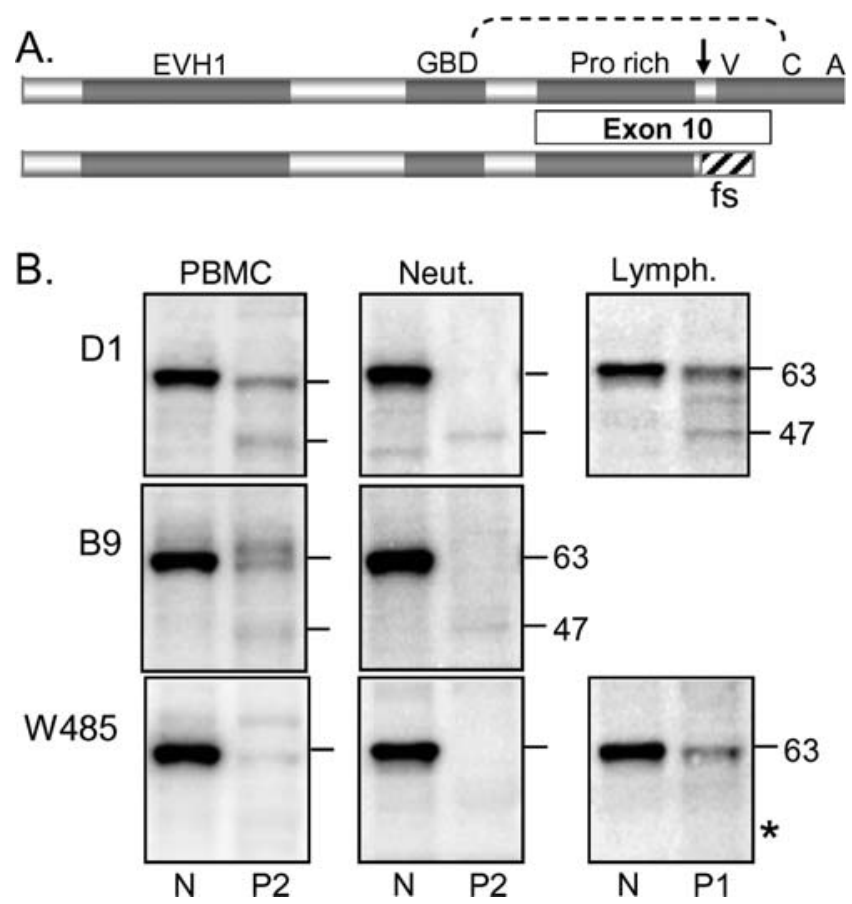

Figure 2. WASP in Patient T Cells Revealed by Western Blot. (A) Schematic of (top) normal WASP (502 amino acids) and (bottom) WASP encoded by the patients' germ line mutation (1305delG in exon 10, arrow) with the frameshifted region (424-443) (fs) indicated. Shown are the upstream regulatory domains: EVH-1, GBD (GTPase binding), and proline-rich region (binding sites for adapter proteins and tyrosine kinases), and the downstream verprolin homology (V) (exon 10), cofilin homology (C) (exon 11) and acidic (A) (exon 12) domains that function in generating actin filaments. The intramolecular bond of autoinhibited WASP is indicated by a dotted line. (B) PBMC, neutrophils and lymphocytes $\left(5 \times 10^{5}\right.$ cells) of normal individuals $(\mathrm{N})$ and patients 1 (P1) and 2 (P2) were stained as indicated with B9 and D1 antibodies to WASP residues $1-250$ and W485 antibody to the C-terminal peptide. The numbers on the right indicate apparent mass $(\mathrm{kDa})$ of WASP bands relative to marker proteins. The asterisk $(*)$ in the W485 blot indicates the position of a $40 \mathrm{kDa}$ marker protein, which was used to verify inclusion of the $47 \mathrm{kDa}$ region. The blots were restained with actin antibodies, which verified equal protein loading (not shown). doi:10.1371/journal.pone.0003444.g002

nucleotide deletion. These encode WASP lacking 4, 5, 6, 7, 11 or 18 amino acids of the linker polypeptide that separates the prolinerich region and the verprolin homology domains (Figure 3, top). The other allele type, small insertions or deletions upstream and in one case downstream of the germ line mutation, were found in 7 of 11 clones for patient 1 . These encode WASP with small out-offrame segments and/or deletions that restore the downstream reading frame (Figure 3, bottom).

Overall, the patients' somatic alleles are highly diverse at the DNA level but have common features at the level of encoded protein. All changes are confined to the linker region, which has no known function, and limited segments of the large proline-rich region. Notably, all 14 somatic alleles restore the translational reading frame encoding the VCA domains required for WASP to function in actin remodeling in contrast to what would be expected from a random assortment of somatic mutations (Figure 3). This strongly suggests that natural selection within lymphocyte populations favors the survival and proliferation of cells expressing these VCA domain-restoring alleles over cells expressing the inherited WASPAVCA allele or somatic mutations that fail to restore protein function. 
Table 2. Somatic WASP Alleles.

\begin{tabular}{|c|c|c|c|c|c|}
\hline Allele\# & Mutation $^{\mathrm{a}}$ & Predicted Effect & $\Delta$ Gene length $^{b}$ & Patient & Source $^{c}$ \\
\hline 1 & 1303-1314del & $424-427 \mathrm{del}$ & $-11 b p$ & patient 2 & $T$ cell $^{G}$ \\
\hline 2 & 1297-1311del & $422-426 \mathrm{del}$ & $-14 b p$ & patient 1 & $T$ cell $^{G}$ \\
\hline \multirow[t]{2}{*}{3} & 1295-1312del & 421-426del & $-17 b p$ & patient 1 & $T$ cell $^{\mathrm{G}}$ \\
\hline & & & & patient 2 & T cell ${ }^{G}, \operatorname{PBMC}^{R}(2 \times)$ \\
\hline 4 & 1301-1321 del & $423-429 \mathrm{del}$ & $-20 \mathrm{bp}$ & patient 2 & $T$ cell $^{\mathrm{G}}$ \\
\hline 5 & 1299-1319del & $422-428 \mathrm{del}, \mathrm{G} 429 \mathrm{R}$ & $-20 \mathrm{bp}$ & patient 2 & $\mathrm{PBMC}^{\mathrm{R}}$ \\
\hline 6 & 1283-1315del & $417-427$ & $-32 b p$ & patient 1 & T cell ${ }^{G}(2 \times)$ \\
\hline 7 & 1275-1328del & 415-432del; P414R & $-53 \mathrm{bp}$ & patient 2 & $\mathrm{~T}_{\text {cell }}{ }^{\mathrm{G}}, \mathrm{PBMC}^{\mathrm{G}}$ \\
\hline 8 & 1323-24insG & $424-429 \mathrm{fs}$ & $+1 \mathrm{bp}$ & patient 1 & $T$ cell $^{G}$ \\
\hline 9 & 1281-82delCT & $417-424 f s$ & $-2 b p$ & patient 1 & $T$ cell $^{\mathrm{G}}$ \\
\hline 10 & 1257-58insA & $409-424 \mathrm{fs}$ & $+1 \mathrm{bp}$ & patient 1 & $T$ cell $^{G}$ \\
\hline 11 & 1243-44ins10bp & $404-424 f s$ & $+10 \mathrm{bp}$ & patient 1 & $T$ cell $^{G}$ \\
\hline 12 & 1218-1261del & 396-409del; 410-424fs & $-44 b p$ & patient 1 & $T$ cell $^{\mathrm{G}}$ \\
\hline 13 & 1211-1239del & 393-402del, 403-424fs & $-29 b p$ & patient 1 & $T$ cell $^{\mathrm{G}}$ \\
\hline 14 & $1113-14$ ins C & $361-424 f s$ & $+1 \mathrm{bp}$ & patient 1 & $T$ cell ${ }^{G}$ \\
\hline
\end{tabular}

${ }^{a}$ Nucleotides and amino acids are numbered relative to normal WASP. Amino acids are identified by single letter code. del, deletion; ins, insertion; fs, frameshift. ${ }^{\mathrm{b}}$ Changes of gene and CDNA length ( $\Delta$ Gene length) are expressed relative to the patients' germ line allele.

${ }^{C}$ Clones indicated by superscript ${ }^{G}$ were generated from genomic DNA; those indicated by superscript ${ }^{R}$ were generated from reverse-transcribed RNA. Except where noted (\# 3, 6 and 7), each allele was cloned once.

doi:10.1371/journal.pone.0003444.t002

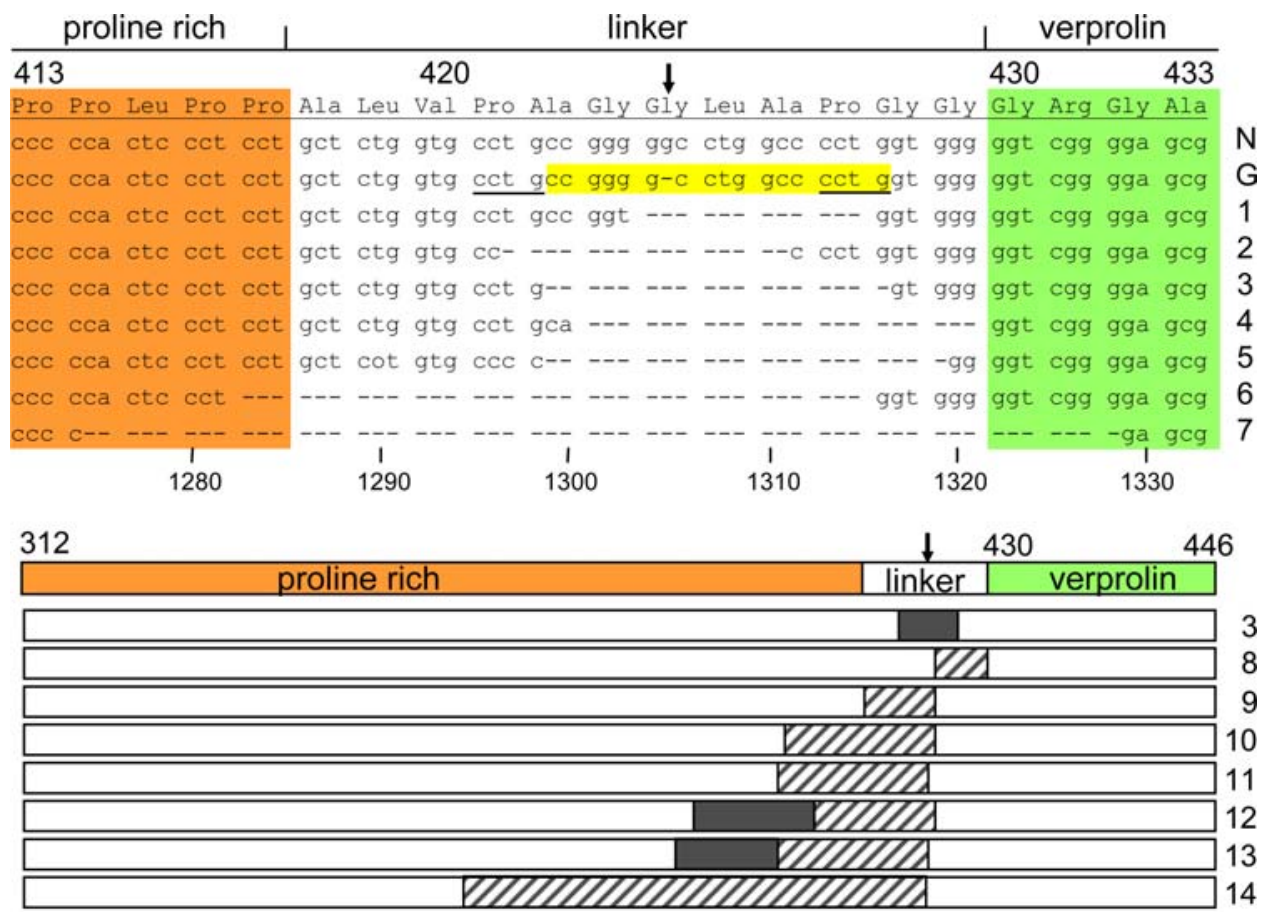

Figure 3. Fourteen Somatic Patient Alleles Identified by Cloning. Top: Alleles 1-7. Shown is the affected segment of exon 10 of normal WASP $(\mathrm{N})$, the patients' germ line allele (G) and somatic alleles \#1-7 (identified on the right). The arrow marks the germ line 1305G deletion. These 7 alleles encode WASP with deletions in the linker region that minimally impinge on the upstream proline-rich region (orange) and do not impinge on the downstream verprolin homology (V) domain (green). Features favorable to mutations include the high GC content and particularly nucleotides 12991316 (yellow), which may form a hairpin loop stabilized by five G-C bonds, and tandem 4 nucleotide repeats (underlined) that could predispose to deletion by slipped strand mispairing. Bottom: Alleles \# 8-14. Shown is the entire exon 10 with $1305 \mathrm{G}$ marked by an arrow. Patient allele \#3 is repeated to facilitate comparison. Deleted segments are shown as black, out-of-frame segments as crosshatched. Numbering is relative to normal WASP. Further details are in Table 2.

doi:10.1371/journal.pone.0003444.g003 


\section{Parallel Evolution of Restored WASP in B Cell Populations in vitro}

We also studied a B cell line from one of the brothers. This was an Epstein-Barr virus (EBV) immortalized line generated 9 years earlier from PBMC of patient 2, who was then 13 years old. When the cell line was first generated, full length WASP was found by quantitative Western blot at $15 \%$ of normal level [27], but later assays showed variably higher levels. To assess whether selection for somatic alleles also occurs in vitro, a remaining aliquot of the earliest cryopreserved immortalized cells was placed in culture. Flow cytometry performed 1 week later showed that $1 \%$ of cells were WASP-positive; however by 6 weeks the frequency of WASPpositive cells had increased to $16 \%$ and by 10 weeks to more than 90\% (Figure 4A and insert). Nearly identical results were obtained on culturing a second aliquot of the cryopreserved cells (data not shown).

Size analysis of amplified exon 10 from the patient cell line at 6 weeks of culture showed a major fragment, 1-bp smaller than normal, consistent with the germ line allele, and a minor fragment smaller by 17 -bp that represented $15 \%$ of amplified DNA (Figure 4B). The long-term cultured cells had only the latter size fragment; its sequence is identical to somatic allele \#3 identified for patient $\mathrm{T}$ cells. Western blots showed time-dependent increase of full-length $(63 \mathrm{kDa})$ WASP concurrent with time-dependent decrease of the $47 \mathrm{kDa}$ apparent truncated WASP protein (Figure 4C). These findings demonstrate a change in the allele frequency within the cell line due to natural selection acting through an in vitro survival and/or proliferation advantage for WASP gene-corrected B-cells relative to germ line encoded B-cells.
Diversity of Somatic Alleles Expressed in Patient T cells

The WASP protein in patient $\mathrm{T}$ cells could have been transcribed primarily from a single allele if most somatic mutations persisted in cells and were only occasionally transcribed. To distinguish between this possibility and that of multiple transcribed somatic alleles, we subjected amplified reverse-transcribed RNA and amplified genomic DNA to size analysis by high resolution electrophoresis. On size analysis, RNA-derived fragments from $\mathrm{T}$ cells and NK cells of normal healthy individuals migrated as single peaks at the predicted 284 bp (Figure 5, top row, left and middle), and patient NK-cell fragments migrated as a single 283 bp peak, consistent with the germ line allele (Figure 5, row 2, left), indicating that transcribed WASP in these cell populations comes from a single source allele. In contrast, the results for the patients clearly showed multiple peaks in T cell genomic DNA and in T cell RNA (Figure 5 rows 2, 3), demonstrating that "full length" WASP protein detected by Western blot of patient $\mathrm{T}$ cells is a mixture of differently "corrected" WASP proteins synthesized by cells expressing different somatic alleles.

Through high resolution electrophoresis we also aimed to describe the diversity of WASP RNA size classes. Densitometry indicated that $58 \%$ of $\mathrm{T}$ cell RNA of patient 2 differs in size from the germ-line allele. This is consistent with the $56 \%$ of T cells that are WASP-positive as identified by flow cytometry. Both his RNAand DNA-derived products consisted of discrete peaks that included the germ line fragment and somatic fragments lacking $8,11,14$ or 17 bp relative to the germ line fragment. For patient 1 , individual novel peaks were less prominent, consistent with the greater diversity of this patient's somatic alleles. The "germ line"

A.
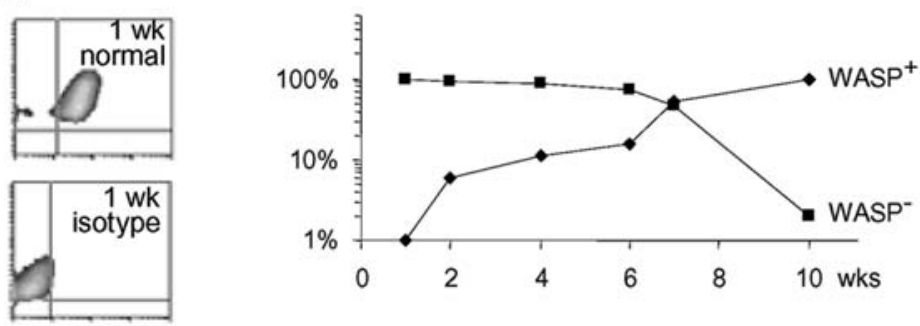

(y)
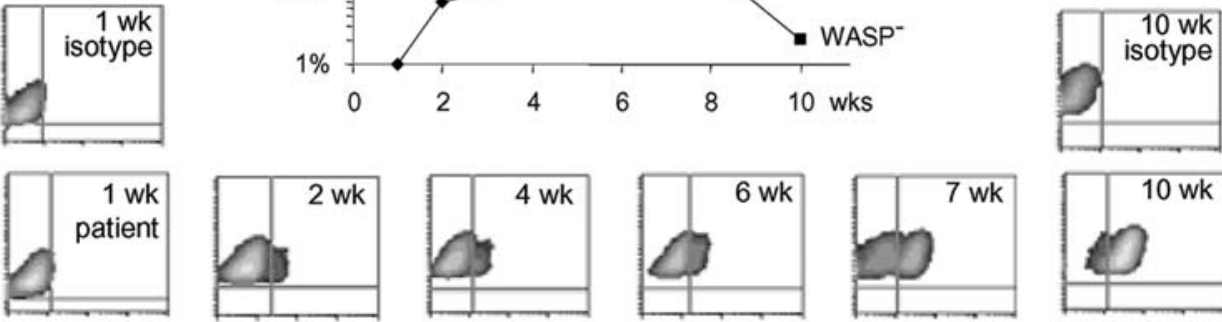

WASP

B.

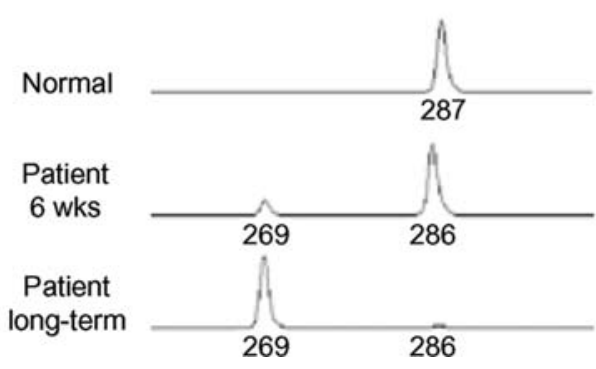

C.

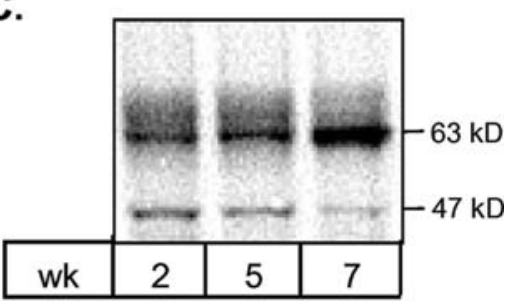

Figure 4. Changes in WASP Over Time of Culture of an EBV-transformed B Lymphoblastoid Cell Line of Patient 2. Cryopreserved cells from the earliest freeze of the transformed cell line were placed in culture and sampled at the indicated times. (A) WASP expression analyzed by flow cytometry after intracellular staining with B9 WASP antibody or isotype control. The insert shows the relative frequency of WASP ${ }^{+}$and WASP ${ }^{-}$ populations on a log scale. (B) Fragment length analysis of amplified exon 10 of a normal B cell line (top), the patient B cell line at 6 weeks (middle) and after long term culture (bottom). (C) Western blot of cells harvested at 2, 5 or 7 weeks and stained with B9 antibody to reveal full-length (63 kDa) WASP and $47 \mathrm{kDa}$ truncated WASP.

doi:10.1371/journal.pone.0003444.g004 


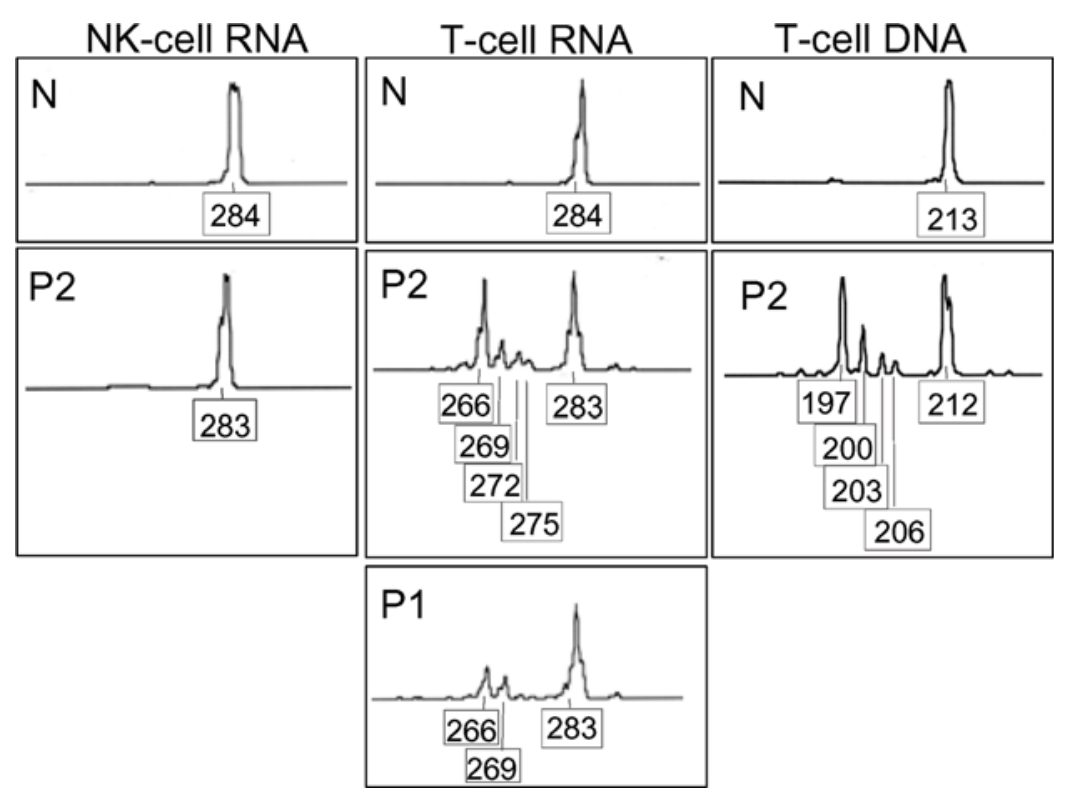

Figure 5. Fragment Length Analysis of Patient mRNA. Messenger RNA of T cells and NK cells was reverse-transcribed, and WASP was amplified from nucleotide 1151 in exon 10 to 1434 in exon 11, and the products were separated by capillary electrophoresis. Shown are products derived from RNA of NK cells (left) or T cells (middle) of a normal individual (N) or patient 2 (P2) or T cells of patient 1 (P1). Shown in the right panels are amplified exon 10 regions of genomic DNA. Fragment lengths $(\mathrm{bp})$ are indicated. doi:10.1371/journal.pone.0003444.g005

peak was broad, probably encompassing the patient's $1 \mathrm{bp}$ insertions and $2 \mathrm{bp}$ deletions, confounding quantitation of the percent of RNA that is somatic vs. germline. Conservatively, at least 2 somatic alleles made up 39\% of the WASP RNA in T cells of patient 1.

Of the novel fragment size classes identified for patient 2, two, the fragments lacking $8 \mathrm{bp}$ relative to the germ line allele and those lacking $14 \mathrm{bp}$, are not represented among the patient's cloned alleles. The presence of size classes of patient 2 RNA and genomic DNA that are not accounted for by the cloned alleles together with broad peaks for patient 1 indicate that the brothers have additional somatic alleles not identified in the study. These findings suggest that the identified somatic WASP alleles represent the "tip of the iceberg" of diversity of the patients' T cells.

\section{Discussion}

Here we document the independent evolution of polymorphic $\mathrm{T}$ cell populations involving many somatic alleles in two brothers who inherited a frameshift mutation of WASP. As a result of selection for somatic alleles, the brothers' lymphocyte compartments are somatic mosaics and their gene-corrected cells are identifiable by WASP expression. The somatic alleles are compensatory because they ( $i$ support WASP expression at approximately normal levels in certain patient cells and (ii) confer an apparent selective advantage in the generation of memory $\mathrm{T}$ cells and B cells. WASP mRNA in the patients' T cells had varying size, indicating that multiple somatic alleles are indeed expressed. The somatic alleles differed between the two brothers - both in the type of clones isolated and the fragment length patterns. This implies a random process at the level of generation of somatic mutations. In contrast, the quantitative enrichment of somatic alleles and their distribution among lymphocyte populations were indistinguishable between the brothers, speaking for the uniformity of the selection (enrichment) forces.

Somatic alleles were first described for primary immune deficiency for a patient with adenosine deaminase deficiency
[28] and subsequently for WAS. In general, detection of a somatic mutation indicates that a new allele provides a differentiation, growth or survival advantage for the cell population(s) in which it appears. Historically, somatic alleles have been considered rare, however results obtained with newer detection methods suggest that they occur with greater frequency than previously thought, at least for genetic hematopoietic diseases (as outlined in Introduction). For example, by testing antibody stained cells by flow cytometry, an international consortium recently documented somatic WASP alleles, either reversions or second site mutations, in $11 \%$ of 272 WAS patients [29]. These somatic mutations of WASP led to a variety of enrichment patterns: T cells only were most frequent, followed by $\mathrm{T}$ plus NK cells or T plus B cells. The different enrichment patterns are thought to reflect the developmental stage at which the somatic allele arose (stem cell vs. multipotent progenitor or lineage committed progenitor) and the importance of WASP in further differentiation, proliferation and survival of the affected lineage(s). A recent publication reports on another WAS patient with multiple somatic alleles [30], and thus, the brothers described here are the second and third reported cases of multiple somatic alleles in WAS. Although their disease has features shared with single somatic allele patients, most notably the preferential enrichment of somatic alleles in memory $\mathrm{T}$ cells $[9,10]$, other important features of their phenotype are specific to multiple somatic alleles.

\section{Germ Line Allele Confers a Large Cost in T-Cells During Lymphopoiesis}

The unique features of the brothers' disease are, first of all, the large number of somatic alleles. Cloning identified 15 alleles, 10 for one brother and 5 for the other. However, the true total is likely to be much larger as suggested by fragment analysis, which revealed size classes of alleles that are not present in the clones. A larger repertoire is also suggested by the paucity of repeatisolations of clones with the same sequence, i.e., 15 of 19 clones had unique sequence, indicating that we have not come close to a 
saturated sample of the population. Secondly, the somatic alleles are diverse. Among those that were cloned, six code for deletions of varying size (11-53 bp) surrounding the germ line mutation, four have small indels $(+1$ or $-2 \mathrm{bp})$ at locations ranging from nucleotide 1113 to nucleotide 1323, and three have deletions or insertions of 10-44 bp upstream of the inherited mutation.

Whereas diversity is broad, the range of affected cells is narrow - primarily T cells and to a much smaller extent B cells. Sensitive techniques of flow cytometry, Western blot, and fragment length analysis were used to search for somatic alleles in the brothers' monocytes, neutrophils and NK cells. Only the germ line allele was found in these cells, indicating that the brothers do not have genetic instability at the WASP locus. Indeed, based on the collective findings, there is no reason to postulate that mutation of WASP in the brothers' cells occurs at anything other than the normal random rate. Instead, the much higher rate at which new somatic alleles have become detectable in these patients indicates a unique combination of timing and magnitude of selection against their inherited allele. A further unusual feature of the brothers' disease is that their blood cells that carry the germ line allele express truncated WASP. We propose that the multiplicity and diversity of their somatic alleles relative to other WAS germ line alleles is due to a deleterious effect of the presence of truncated WASP over and above the cost of absence of full-length WASP.

\section{Role of WASP Domains in T Cell Lymphopoiesis}

Normal hematopoietic precursor cells generated in the bone marrow migrate to the thymus where they commit to the Tlineage and undergo programmed differentiation becoming first CD4/CD8 double negative (DN) thymocytes, then CD4/CD8 double positive (DP) and finally either CD4 single positive (SP) or CD8 SP thymocytes [31]. These stages differ in transcriptional, translational, migratory and proliferative activities. In mice, DN thymocytes are further distinguished as stages 1 (DN1) through 4 (DN4). Progression from DN3 to DN4 and DP depends on rearrangement of the germ line $\mathrm{T}$ cell receptor $\beta$-chain (TCR- $\beta$ ) and expression on the cell surface of pre-TCR (TCR- $\beta$ associated with germ line pre- $\alpha$ chain). The TCR $\alpha$-chain is rearranged in DP cells and successful rearrangement results in expression of a unique TCR on DP cells. The specificity of the unique TCR is the basis for positive selection and those clones that recognize self peptides in the context of self histocompatibility proteins with moderate affinity will be selected. The majority of DP cells fail to recognize self peptides and die by apoptosis. Positively selected DP cells further mature into SP cells. Both DP and SP cells undergo negative selection to deplete clones with high affinity for self antigen (e.g. autoreactive $\mathrm{T}$ cell clones); this step is the basis of central tolerance. Only the small fraction of thymocytes that survive positive and negative selection emerge from the thymus to join the pool of peripheral antigen-inexperienced (naïve) CD4 cells or CD8 cells. In ideal situations, this pool provides an adequate number of naive T-cells with the broad diversity of TCRs required for immune protection.

\section{Selection against the Presence of WASP AVCA}

An allele similar to the patients' germ line mutation was previously studied in mice and found to be extremely deleterious in $\mathrm{T}$ cells. Whereas WAS patients and mice that lack WASP have modest deficits of $\mathrm{T}$ cells [18,32], mice engineered to express wasp $\triangle V C A$ have profoundly decreased numbers of peripheral $\mathrm{T}$ cells and severely decreased thymic cellularity with $12-16 \%$ of the normal number of thymocytes [33]. On analysis of thymocyte subpopulations, the defect in wasp $\Delta$ VCA mice was traced to a profound block at DN3 thymocytes after TCR- $\beta$ rearrangement.
The extremely deleterious effect of wasp $\Delta$ VCA implies that the truncated protein interferes with a function crucial to survival of DN3 thymocytes or their progression to DN4 and DP thymocytes.

Zhang and colleagues postulated that wasp $\Delta$ VCA might interfere with the function of a redundant protein such as $\mathrm{N}$ WASP or WAVE-2 [33]. N-WASP, WASP and the (three) WAVE proteins are members of the WASP protein family; each contains a VCA domain and functions in actin cytoskeletal regulation [34]. We consider the WAVE protein an unlikely candidate because WASP-WAVE homology is limited to the WASP C-terminal region. In contrast, N-WASP and WASP share homologies that include the N-terminal domains retained in WASPAVCA. These domains function in recruiting WASP/N-WASP to sites of activation and in binding ligands that convert autoinhibited WASP/N-WASP to the active form $[15,17]$. We thus anticipate that truncated WASPAVCA encoded by the patients' germ line allele will retain the ability to bind to effector ligands, potentially competing with the ability of N-WASP to perform a redundant function. A dominant block of thymocyte maturation due to competitive inhibition of N-WASP would provide a strong selective advantage to a mutation in which the VCA domain is restored. This makes WASPAVCA a dominant negative mutation in that the truncated protein interacts with effectors as the wildtype protein does, but blocks its function.

Supporting evidence for selection against the presence of WASP $\triangle$ VCA is provided by a recent study in which WASP and $\mathrm{N}$-WASP were deleted in murine T cells. Whereas deletion of $\mathrm{N}$ WASP on a wild type background did not alter $\mathrm{T}$ cell development, deletion of both WASP and N-WASP severely compromised $\mathrm{T}$ cell development, producing a phenotype similar to that of wasp $\triangle V C A$ mice, i.e., marked thymic hypocellularity and reduced number of peripheral $\mathrm{T}$ cells with blockage at the level of DN3 thymocytes [35]. We conclude that for WASP mutations resulting in no protein expression at all, N-WASP partially compensates for lack of WASP in supporting the DN3 to DP transition, but that WASP $\triangle$ VCA, because it expresses the $\mathrm{N}$ terminal portion of WASP, competes with the ability of N-WASP to compensate for WASP function.

Thus, we propose that, in addition to the deleterious effects conferred by the absence of functional WASP, the patients' thymocytes expressing WASP $\triangle$ VCA encounter a block to differentiation/ proliferation at the human counterpart of the murine DN3 stage (described above), and the block creates an unusually strong selective advantage for thymocytes bearing beneficial somatic mutations. As a result, thymocytes with correcting somatic mutations increase in frequency as they replicate and progress through the final double negative stage to become $\mathrm{CD} 4^{+} \mathrm{CD} 8^{+} \mathrm{DP}$ thymocytes. Under this hypothesis, the population released to the periphery as CD4 or CD8 naïve T cells would be smaller than normal, but already enriched for correcting alleles.

Of note, the effect of germline WASP $V C A$ differs quantitatively between the patients and the mouse model, in that the brothers have decreased but readily detectable numbers of WASP-negative circulating $\mathrm{T}$ cells whereas wasp $\triangle V C A$ mice have a nearly complete block of mature $\mathrm{T}$ cell generation. This discrepancy may reflect a different effect of WASP $V C A$ in mice vs. humans. However, it also needs to be considered that the expression level of wasp $\Delta$ VCA in the mouse transgenic model approximates the normal wasp expression level. In contrast, the $47 \mathrm{kDa}$ apparent truncated WASP $\triangle$ VCA protein is present at low levels in patient blood cells (Figures 1 and 4). Thus the lesser impact on $\mathrm{T}$ cell generation in the patients may be due to lower concentration of potentially blocking truncated WASP protein, i.e., a quantitative rather than a qualitative difference. 


\section{Timing of Selection against WASP $A V C A$}

The disadvantage for WASPAVCA germ line thymocytes is apparently enormous since it is sufficient to drive multiple independent somatic mutations to detectable frequencies. However, the extent to which any compensatory alleles can increase in frequency is limited because thymocytes are short-lived intermediates in $\mathrm{T}$ cell differentiation that lack the capacity for self renewal. The multiplicity of somatic alleles in the patients' $\mathrm{T}$ cells and the failure of any one allele to become fixed in the population are consistent with the selective advantage occurring at a relative late stage in $\mathrm{T}$ cell differentiation and explain why the absolute number of gene-corrected $\mathrm{T}$ cells is not sufficient to fill the naïve $\mathrm{T}$ cell compartment. Quite apart from mechanistic questions, the paucity of the patients' gene-corrected naïve $\mathrm{T}$ cells is a concern for their immune protection.

\section{Further Selection in the Periphery}

The greater frequency of somatic alleles in the brothers' memory $\mathrm{T}$-cells compared to naïve $\mathrm{T}$ cells indicates that further selection occurs after mature SP thymocytes enter the peripheral circulation as naïve T cells. Naïve T cell population size is controlled by thymic output and access to cytokine survival factors and, to a limited extent, by cell replication (reviewed in [36]). Thus the selection against presence of WASP $\triangle$ VCA directly affects this cell population. Because memory $\mathrm{T}$ cells are generated from naïve $\mathrm{T}$ cells by antigen-induced differentiation and clonal expansion, differential clonal expansion, e.g., by selection for cells with functional WASP, must explain the greater frequency of gene corrected memory $\mathrm{T}$ cells. Such enrichment by differential clonal expansion was previously identified for an atypical patient, a female with the genotype of a WAS carrier, but with circulating white blood cells that were a mixture of WASP-negative and WASP-positive cells due to failure of early hematopoietic selection. In contrast, memory $\mathrm{T}$ cells of that patient were primarily WASP-positive [37]. This second selective event occurring in peripheral $\mathrm{T}$ cells has been described also for WAS patients with single somatic alleles (e.g., [9]), and is consistent with the known role of WASP in antigen receptor mediated (TCR-mediated) activation of naive T cells [16,38,39].

The flip side of the phenomenon that naive $\mathrm{T}$ cells bearing a somatic allele are preferentially recruited to become memory $\mathrm{T}$ cells is the selective depletion of gene-corrected naïve T cells. This explains why we don't see somatic allele enrichment in the standing naïve $\mathrm{T}$ cell population as one might have anticipated based on the hypothesized processes occurring in the thymus. From the perspective of immune repertoire, the patients may simply have two few gene-corrected naïve $\mathrm{T}$ cells for normal immune protection.

\section{Somatic Alleles in B Cells}

$\mathrm{B}$ cells were also examined for the presence of somatic alleles, although the scope of the study was limited by the paucity of $\mathrm{B}$ cells in blood of these patients. Gene-correction was found in B cells of both brothers at levels sufficient for detection of the protein by flow cytometry. Moreover, the somatic allele(s) was strongly enriched in patient memory B cells, $40 \%$ of which were WASPpositive compared to $1 \%$ of naïve $\mathrm{B}$ cells. It is unclear whether the patients' precursor B cells underwent repeated selection events to generate more than one somatic allele.

Similarly to a previous report of somatic allele enrichment in a patient cell line [8], we found that in vitro culture of the patient B cell line reproducibly resulted in an increase of a somatic allele from $1 \%$ to close to fixation and concurrent depletion of the germ line allele and the truncated WASP protein. Whether the selected allele that we identified for the patient $\mathrm{B}$ cell line arose in vitro or in vivo cannot be distinguished. Regardless, these in vitro evolutions demonstrate a survival and/or proliferative advantage of the somatic allele over the germ line allele in competition in cell culture.

\section{Significance of Multiple Somatic Alleles}

A principle difference exists between single $v s$. multiple somatic alleles. This difference follows directly from population genetic principles but is not obvious without this evolutionary perspective. A single somatic corrective allele can be thought of as a "jackpot" effect - a chance mutation occurring sufficiently early in maturation of a cell lineage(s) in which the germ line allele has a cost. Each patient with a "jackpot" correction will have a single somatic allele, but a different correcting allele might be found in another patient. In contrast, the presence of multiple somatic alleles in an individual patient indicates that a more deterministic process is occurring. We therefore compare the brothers with other well-characterized primary immunodeficient patients for whom more than one somatic allele was reported.

The first reported case involved the RAG1 gene (Recombination Activating Gene-1) in a patient with Omenn's syndrome, a primary

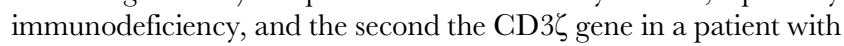
severe combined immunodeficiency (SCID) [40,41]. Each of these patient's somatic alleles apparently benefited from a proliferative advantage relative to the defective germ line allele at a specific stage of thymocyte development. The gene-corrected cells lacked the capacity of hematopoietic stem/progenitor cells for self renewal and unlimited expansion and only partially filled the T cell compartment. We conclude that the presence of multiple somatic alleles in a primary immunodeficiency patient indicates that $(i)$ a developmental stage is severely affected by the germ line allele of that patient and (ii) the affected developmental stage occurs post self-renewal capacity. Because population size post self-renewal will be large, many mutations will be present and strong selection will produce many different compensatory alleles. Based on the underlying population genetics, one anticipates that this will happen in all individuals who carry a particular germ line allele. This explains the similar frequency but different spectrum of somatic alleles in the two brothers. A recent report describes another WAS patient for whom 34 somatic alleles were identified [30]. This patient's germ line allele, also an exon 10 mutation, is predicted to result in a truncated WASP protein missing not only the VCA domain but also most of the proline-rich region. Once the range of cells expressing the patient's somatic alleles has been identified and the phenotype of his germ line allele clarified at the level of the protein and cell, we may well find that his case is another example of selection against the

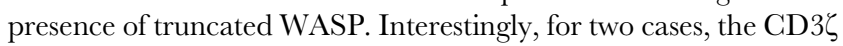
patient and the brothers with WAS, truncated protein was found in patient cells with the germ line mutation. This suggests that (iii) multiple somatic alleles may indicate that the germ line allele has a dominant negative effect.

Thus, a finding of multiple somatic alleles in a single individual serves to "flag" an inherited allele harboring unique information. It has potential to contribute toward identifying tightly regulated maturational steps and providing clues to the specific function of the gene product at the particular developmental stage.

\section{Methods}

\section{Patients}

Patient 1 , a white male, was 25 years old at the time most of these studies were done. The diagnosis of the WAS was made in infancy because of petechial hemorrhages and a positive family history. At 3 years of age a splenectomy was performed because of persistent thrombocytopenia. His subsequent growth and devel- 
opment were normal. He developed mild eczema of the extremities at an early age. During his teenage years he had recurrent Molluscum contagiosum infection of the eczematous areas of his skin. At age 16 he developed moderate to severe symmetrical arthralgias with joint swelling and immune complex uveitis. At age 21 he complained of low back pain. A diagnosis of sacral osteomyelitis was established, due to Staphylococcus aureus, and successfully treated with antibiotics.

The brother, patient 2, was 22 years old at the time most of these studies were done. Appearance of petechiae in the neonatal period led to the diagnosis of the WAS. A splenectomy was performed at age 3 years. He continued thereafter, like his brother, to take daily antibiotic prophylaxis and intravenous gamma globulin at 4-week intervals. Except for otitis media, he did not have serious infections. He was admitted to the hospital at age 7 because of severe otitis externa, which was treated with carbenicillin and gentamycin. He never had significant eczema. Subsequent to the experimentation reported here, patient 2 developed non-Hodgkin $\mathrm{T}$ cell lymphoma. He was successfully treated by cord blood transplantation.

\section{Cell Analysis and Isolation}

Blood samples were collected with informed consent from the patients and healthy control individuals using acid-citrate-dextrose (NIH formula A) as anticoagulant under protocols approved by the Institutional Review Board of the Immune Disease Institute. The patients in this manuscript have given written informed consent (as outlined in the PLoS consent form) to publication of their case details. The blood was examined immediately or after overnight shipment at ambient temperature. Cell populations were quantified using the Max-M cell counter (Coulter Corp, Hialeah, FL) and by flow cytometry after staining aliquots of whole blood with combinations of marker antibodies as described [18]. To isolate specific cell populations, the blood was processed by differential centrifugation as described [26]. Density centrifugation on Histopaque 1077 (Sigma, St Louis, MO) was used to separate the peripheral blood mononuclear cells (PBMC) (lymphocytes plus monocytes) from the neutrophils. Lymphocytes were isolated from PBMC by depleting monocytes by adherence to serum-coated plates. Lymphocytes were isolated from PBMC by negative immunomagnetic selection and natural killer lymphocytes (NK lymphocytes) were isolated by positive immunomagnetic selection with CD56 antibody (reagents from Dynal Biotech, Oslo, Norway).

\section{Flow Cytometry}

PBMC $\left(5 \times 10^{5}\right)$ in $50 \mu \mathrm{l}$ phosphate buffered saline with $1 \%$ fetal calf serum (PBS-FCS) or whole blood $(100 \mu \mathrm{l})$ were surface-stained with phycoerythrin (PE) or phycocyanin-5 (PC5)-labeled CD3, CD19, CD4, CD8, CD16, CD27, CD45RA and CD56, or IgG1 control antibodies (Beckman Coulter, Hialeah, FL) for $15 \mathrm{~min}$ at $\sim 22^{\circ} \mathrm{C}$. Whole blood was lysed with FACS $^{\mathrm{TM}}$ Lysing Solution (BD Biosciences, Palo Alto, CA) for $15 \mathrm{~min}$ at $\sim 22^{\circ} \mathrm{C}$. After washing with $3 \mathrm{ml}$ PBS-FCS, the cells were incubated in $250 \mu \mathrm{l}$ of Fix/Perm solution (Pharmingen, San Diego, CA) for 20 min on ice, washed twice, stained with $5 \mu \mathrm{g} / \mathrm{ml}$ of B9 anti-WASP monoclonal antibody (Santa Cruz, Santa Cruz, CA) or IgG2a isotype control (Pharmingen) for $30 \mathrm{~min}$ on ice, and washed twice with Perm/Wash solution. The cells were incubated with $10 \mu \mathrm{g} /$

\section{References}

1. Wiskott A (1936) Familiarer, angeobren Morbus Werlhofi? Monatschrift Kinderheil 68: 212. $\mathrm{ml}$ of fluorescein isothiocyanate- (FITC-) conjugated goat antibody to mouse IgG2a (Southern Biotechnology, Birmingham, AL) for $30 \mathrm{~min}$, washed twice with Perm/Wash solution, re-suspended in $50 \mu \mathrm{l}$ PBS and analyzed immediately on the FACS Calibur by collecting 10,000 cells/sample. Individual cell populations were separately evaluated by gating based on forward and side scatter and/or expression of surface markers.

\section{Western Blots}

Isolated PBMC, lymphocytes and neutrophils were washed, treated with protease inhibitors and lysed with an SDS solution containing 2-mercaptoethanol as described [26]. The lysates were fractionated by SDS electrophoresis, transferred electrophoretically to polyvinylidene difluoride (PVDF) membrane, which was blocked, washed and incubated with affinity-purified rabbit W485 antibody to WASP [27] or mouse D1 or B9 monoclonal antibodies to WASP (Santa Cruz Biotechnology, Santa Cruz, CA). After further washes, the membrane was incubated with ${ }^{125}$ I labeled goat antibodies to rabbit immunoglobulin or rabbit antibodies to mouse immunoglobulin [26]. Where indicated, WASP bands were quantified using the Storm 860 Imager and Image Quant (Molecular Dynamics, Sunnyvale, CA).

\section{DNA and RNA Analysis}

Genomic DNA was isolated using QiaAmp DNA purification kit (Qiagen, Valencia, CA). WASP exon 10 was amplified for cloning with intron primers [42], and PCR products were gelpurified and cloned into pSTBlue-1 (Novagen, Darmstadt, Germany). RNA was isolated using Trizol (Invitrogen, Carlsbad, CA) and was reverse-transcribed $(2 \mu \mathrm{g}$ in $20 \mu \mathrm{l})$ with oligo-dT $(1 \mu \mathrm{g})$ Superscript II (200 units) (Promega, Madison, WI) at $45^{\circ} \mathrm{C}$ for $50 \mathrm{~min}$. WASP cDNA was amplified for cloning from WASP 906 to 1706 with $5^{\prime}$-acgacttcattgaggaccag- $3^{\prime}$ and 5-tgagtgtgaggaccaggcag-3' (1 $\mu \mathrm{M}$ of each), $2 \mathrm{mM} \mathrm{MgSO}{ }_{4}, 0.2 \mathrm{mM}$ dNTPs, and 2.5 U Platinum Taq High Fidelity polymerase (Invitrogen) at $95^{\circ} \mathrm{C}$ for $2 \mathrm{~min}, 35$ cycles at $95^{\circ} \mathrm{C}$ for $30 \mathrm{~s}, 57^{\circ} \mathrm{C}$ for $30 \mathrm{~s}, 72^{\circ} \mathrm{C}$ for $1 \mathrm{~min}$ with $10 \mathrm{~min}$ extension at $72^{\circ} \mathrm{C}$. For high resolution fragment length analysis, RNA was reverse-transcribed, and cDNA and also genomic DNA were amplified using 6-carboxyfluorescein (FAM) labeled 5'-tccagctactggacgttctg-3' together with unlabeled $5^{\prime}$-accagtccctctgagctctg-3' (cDNA) or $5^{\prime}$-cttgttcagctgaattccctgcag-3' (T-cell genomic DNA) or $5^{\prime}$-tcctgacttagacgggacac-3' (B-cell genomic DNA). The products were separated by capillary electrophoresis

\section{Acknowledgments}

We are grateful to our late colleague Fred S. Rosen who cared for the brothers for many years, for providing the description of their disease and for encouraging the study. We thank the brothers for their enthusiastic support. We thank Luigi Notarangelo and Lisa Westerberg for critical review of the manuscript, Erwin Gelfand for facilitating blood specimen collection, Lauren Jones for preliminary experiments, and Jessica Cooley for contributing to blood cell processing.

\section{Author Contributions}

Conceived and designed the experiments: MIL JYP ERO. Performed the experiments: MIL JYP. Analyzed the data: MIL SR ERO. Wrote the paper: SR ERO.

2. Sullivan KE, Mullen CA, Blaese RM, Winkelstein JA (1994) A multiinstitutional survey of the Wiskott-Aldrich syndrome. J Pediatr 125: 876-885. 
3. Filipovich AH, Stone JV, Tomany SC, Ireland M, Kollman C, et al. (2001) Impact of donor type on outcome of bone marrow transplantation for WiskottAldrich syndrome: collaborative study of the International Bone Marrow Transplant Registry and the National Marrow Donor Program. Blood 97: 1598-1603.

4. Imai K, Morio T, Zhu Y, Jin Y, Itoh S, et al. (2004) Clinical course of patients with WASP gene mutations. Blood 103: 456-464

5. Chinen J, Puck JM (2004) Perspectives of gene therapy for primary immunodeficiencies. Curr Opin Allergy Clin Immunol 4: 523-527.

6. Cavazzana-Calvo M, Fischer A (2007) Gene therapy for severe combined immunodeficiency: are we there yet? J Clin Invest 117: 1456-1465.

7. Ariga T, Yamada M, Sakiyama Y, Tatsuzawa O (1998) A case of WiskottAldrich syndrome with dual mutations in exon 10 of the WASP gene: an additional de novo one-base insertion, which restores frame shift due to an inherent one-base deletion, detected in the major population of the patient's peripheral blood lymphocytes. Blood 92: 699-701.

8. Ariga T, Kondoh T, Yamaguchi K, Yamada M, Sasaki S, et al. (2001) Spontaneous in vivo reversion of an inherited mutation in the Wiskott-Aldrich syndrome. J Immunol 166: 5245-5249.

9. Wada T, Schurman SH, Otsu M, Garabedian EK, Ochs HD, et al. (2001) Somatic mosaicism in Wiskott-Aldrich syndrome suggests in vivo reversion by a DNA slippage mechanism. Proc Natl Acad Sci U S A 98: 8697-8702.

10. Wada T, Konno A, Schurman SH, Garabedian EK, Anderson SM, et al. (2003) Second-site mutation in the Wiskott-Aldrich syndrome (WAS) protein gene causes somatic mosaicism in two WAS siblings. J Clin Invest 111: 1389-1397.

11. Jin Y, Mazza C, Christie JR, Giliani S, Fiorini M, et al. (2004) Mutations of the Wiskott-Aldrich Syndrome Protein (WASP): hotspots, effect on transcription, and translation and phenotype/genotype correlation. Blood 104: 4010-4019.

12. Lutskiy MI, Beardsley DS, Rosen FS, Remold-O'Donnell E (2005) Mosaicism of NK cells in a patient with Wiskott-Aldrich syndrome. Blood 106: 2815-2817.

13. Du W, Kumaki S, Uchiyama T, Yachie A, Yeng Looi G, et al. (2006) A secondsite mutation in the initiation codon of WAS (WASP) results in expansion of subsets of lymphocytes in an Wiskott-Aldrich syndrome patient. Hum Mutat 27: 370-375.

14. Burns S, Cory GO, Vainchenker W, Thrasher AJ (2004) Mechanisms of WASpmediated hematologic and immunologic disease. Blood 104: 3454-3462.

15. Rohatgi R, Ma L, Miki H, Lopez M, Kirchhausen T, et al. (1999) The interaction between N-WASP and the Arp2/3 complex links Cdc42-dependent signals to actin assembly. Cell 97: 221-231.

16. Sims TN, Soos TJ, Xenias HS, Dubin-Thaler B, Hofman JM, et al. (2007) Opposing effects of PKCtheta and WASp on symmetry breaking and relocation of the immunological synapse. Cell 129: 773-785.

17. Prehoda KE, Scott JA, Mullins RD, Lim WA (2000) Integration of multiple signals through cooperative regulation of the N-WASP-Arp2/3 complex. Science 290: 801-806.

18. Park JY, Kob M, Prodeus AP, Rosen FS, Shcherbina A, et al. (2004) Early deficit of lymphocytes in Wiskott-Aldrich syndrome: possible role of WASP in human lymphocyte maturation. Clin Exp Immunol 136: 104-110.

19. Wengler G, Gorlin JB, Williamson JM, Rosen FS, Bing DH (1995) Nonrandom inactivation of the $\mathrm{X}$ chromosome in early lineage hematopoietic cells in carriers of Wiskott-Aldrich syndrome. Blood 85: 2471-2477.

20. Zhu Q Zhang M, Blaese RM, Derry JM, Junker A, et al. (1995) The WiskottAldrich syndrome and X-linked congenital thrombocytopenia are caused by mutations of the same gene. Blood 86: 3797-3804.

21. Lutskiy MI, Rosen FS, Remold-O'Donnell E (2005) Genotype-proteotype linkage in the Wiskott-Aldrich syndrome. J Immunol 175: 1329-1336.

22. Sallusto F, Lenig D, Forster R, Lipp M, Lanzavecchia A (1999) Two subsets of memory $\mathrm{T}$ lymphocytes with distinct homing potentials and effector functions. Nature 401: 708-712.

23. Klein U, Rajewsky K, Kuppers R (1998) Human immunoglobulin (Ig)M+IgD+ peripheral blood $\mathrm{B}$ cells expressing the CD27 cell surface antigen carry somatically mutated variable region genes: CD27 as a general marker for somatically mutated (memory) B cells. J Exp Med 188: 1679-1689.

24. Agematsu K, Hokibara S, Nagumo H, Komiyama A (2000) CD27: a memory Bcell marker. Immunol Today 21: 204-206.

25. Kwan SP, Hagemann TL, Radtke BE, Blaese RM, Rosen FS (1995) Identification of mutations in the Wiskott-Aldrich syndrome gene and characterization of a polymorphic dinucleotide repeat at DXS6940, adjacent to the disease gene. Proc Natl Acad Sci U S A 92: 4706-4710.

26. Shcherbina A, Rosen FS, Remold-O'Donnell E (1999) WASP levels in platelets and lymphocytes of Wiskott-Aldrich syndrome patients correlate with cell dysfunction. J Immunol 163: 6314 6320.

27. Remold-O'Donnell E, Cooley J, Shcherbina A, Hagemann TL, Kwan SP, et al. (1997) Variable expression of WASP in B cell lines of Wiskott-Aldrich syndrome patients. J Immunol 158: 4021-4025.

28. Hirschhorn R, Yang DR, Puck JM, Huie ML, Jiang CK, et al. (1996) Spontaneous in vivo reversion to normal of an inherited mutation in a patient with adenosine deaminase deficiency. Nat Genet 13: 290-295.

29. Stewart DM, Candotti F, Nelson DL (2007) The Phenomenon of Spontaneous Genetic Reversions in the Wiskott-Aldrich Syndrome: A Report of the Workshop of the ESID Genetics Working Party at the XIIth Meeting of the European Society for Immunodeficiencies (ESID). Budapest, Hungary October 4-7, 2006. J Clin Immunol.

30. Davis BR, Dicola MJ, Prokopishyn NL, Rosenberg JB, Moratto D, et al. (2008) Unprecedented diversity of genotypic revertants in lymphocytes of a patient with the Wiskott-Aldrich Syndrome. Blood.

31. von Boehmer H, Aifantis I, Gounari F, Azogui O, Haughn L, et al. (2003) Thymic selection revisited: how essential is it? Immunol Rev 191: 62-78.

32. Snapper SB, Rosen FS, Mizoguchi E, Cohen P, Khan W, et al. (1998) WiskottAldrich syndrome protein-deficient mice reveal a role for WASP in T but not B cell activation. Immunity 9: 81-91.

33. Zhang J, Shi F, Badour K, Deng Y, McGavin MK, et al. (2002) WASp verprolin homology, cofilin homology, and acidic region domain-mediated actin polymerization is required for T cell development. Proc Natl Acad Sci U S A 99: $2240-2245$.

34. Takenawa T, Miki H (2001) WASP and WAVE family proteins: key molecules for rapid rearrangement of cortical actin filaments and cell movement. J Cell Sci 114: 1801-1809.

35. Cotta-de-Almeida V, Westerberg L, Maillard MH, Onaldi D, Wachtel H, et al. (2007) Wiskott Aldrich syndrome protein (WASP) and N-WASP are critical for T cell development. Proc Natl Acad Sci U S A 104: 15424-15429.

36. Almeida AR, Rocha B, Freitas AA, Tanchot G (2005) Homeostasis of T cell numbers: from thymus production to peripheral compartmentalization and the indexation of regulatory T cells. Semin Immunol 17: 239-249.

37. Lutskiy MI, Sasahara Y, Kenney DM, Rosen FS, Remold-O’Donnell E (2002) Wiskott-Aldrich syndrome in a female. Blood 100: 2763-2768.

38. Molina IJ, Sancho J, Terhorst C, Rosen FS, Remold-O'Donnell E (1993) T cells of patients with the Wiskott-Aldrich syndrome have a restricted defect in proliferative responses. J Immunol 151: 4383-4390.

39. Dupre L, Aiuti A, Trifari S, Martino S, Saracco P, et al. (2002) Wiskott-Aldrich syndrome protein regulates lipid raft dynamics during immunological synapse formation. Immunity 17: 157-166.

40. Wada T, Toma T, Okamoto H, Kasahara Y, Koizumi S, et al. (2005) Oligoclonal expansion of $\mathrm{T}$ lymphocytes with multiple second-site mutations leads to Omenn syndrome in a patient with RAG1-deficient severe combined immunodeficiency. Blood 106: 2099-2101.

41. Rieux-Laucat F, Hivroz C, Lim A, Mateo V, Pellier I, et al. (2006) Inherited and somatic CD3zeta mutations in a patient with T-cell deficiency. N Engl J Med 354: 1913-1921.

42. Jones L, Lutskiy M, Cooley J, Kenney D, Rosen F, et al. (2002) A novel protocol to identify mutations in patients with Wiskott-Aldrich syndrome. Blood Cells Mol Dis 28: 392. 